\title{
Solar influenced late Holocene temperature changes on the northern Tibetan Plateau
}

\author{
HE YuXin ${ }^{1}$, LIU WeiGuo ${ }^{2 *}$, ZHAO Cheng ${ }^{1}$, WANG Zheng ${ }^{2}$, WANG HuanYe ${ }^{2}$, LIU Yi ${ }^{3}$, \\ QIN Xian Yan ${ }^{3}$, HU QiHou ${ }^{3}$, AN ZhiSheng ${ }^{2} \&$ LIU ZhongHui ${ }^{*}$ \\ ${ }^{1}$ Department of Earth Sciences, The University of Hong Kong, Hong Kong Special Administrative Region, China; \\ ${ }^{2}$ State Key Laboratory of Loess and Quaternary Geology, Institude of Earth Environment, Chinese Academy of Sciences, Xi'an 710075, China; \\ ${ }^{3}$ Institute of Polar Environment, School of Earth and Space Sciences, University of Science \& Technology, China, Hefei 230026, China
}

Received July 1, 2012; accepted September 12, 2012; published online January 11, 2013

\begin{abstract}
Considerable efforts have been made to extend temperature records beyond the instrumental period through proxy reconstructions, in order to further understand the mechanisms of past climate variability. Yet, the global coverage of existing temperature records is still limited, especially for some key regions like the Tibetan Plateau and for earlier times including the Medieval Warm Period (MWP). Here we present decadally-resolved, alkenone-based, temperature records from two lakes on the northern Tibetan Plateau. Characterized by marked temperature variability, our records provide evidence that temperatures during the MWP were slightly higher than the modern period in this region. Further, our temperature reconstructions, within age uncertainty, can be well correlated with solar irradiance changes, suggesting a possible link between solar forcing and natural climate variability, at least on the northern Tibetan Plateau.
\end{abstract}

northern Tibetan Plateau, alkenones, $U_{37}^{k^{\prime}}$, late Holocene

Citation: He Y X, Liu W G, Zhao C, et al. Solar influenced late Holocene temperature changes on the northern Tibetan Plateau. Chin Sci Bull, 2013, 58: 10531059, doi: 10.1007/s11434-012-5619-8

Numerous paleoclimatic studies have extended the instrumental data to the past $\sim 2000$ years in various parts of the world [1-13]. These studies confirm that global temperatures have varied between relatively cold (i.e. the Little Ice Age, LIA) and warm (i.e. the MWP) conditions. In prendustrial era, natural climate variability has been mainly linked to solar irradiance changes [14-19]. However, substantial scientific uncertainty exists on whether temperatures at the current warm stage are equal to or higher than those during the MWP, the most recent natural warm interval before the industrial period [1,2,7-10,20,21]. A recent analysis suggests that the MWP warmth matches or exceeds the current level in some regions, but not globally [8]. Curiously, they also reported "anomalous coolness" during the MWP in central Eurasia including the northern Tibetan Plateau [8], a region with limited high-quality paleoclimatic reconstruc-

*Corresponding authors (email: zhliu@hku.hk; liuwg@loess.llqg.ac.cn) tions available.

The northern Tibetan Plateau is a climatologically important region as it involves complex interactions between the mid-latitude westerly and subtropical Asia monsoon circulations [22], which may provide a bridge connecting the high and low latitude climatic processes [23]. The temperature records in China have high level-of-confidence for the past 500 years [24-26]. However, large uncertainties exist prior to the 16th century [24].

Lake sediment records could provide climate information on low frequency signals at multi-centennial timescales that may not be captured by tree ring data [9]. Here we worked on two lake sediment cores from the Qaidam Basin on the northern Tibetan Plateau (Figure 1) to obtain decadallyresolved records over the late Holocene period. Our lake records here show persistent warmth during the MWP and the temperature variability likely linked to solar irradiance changes. 


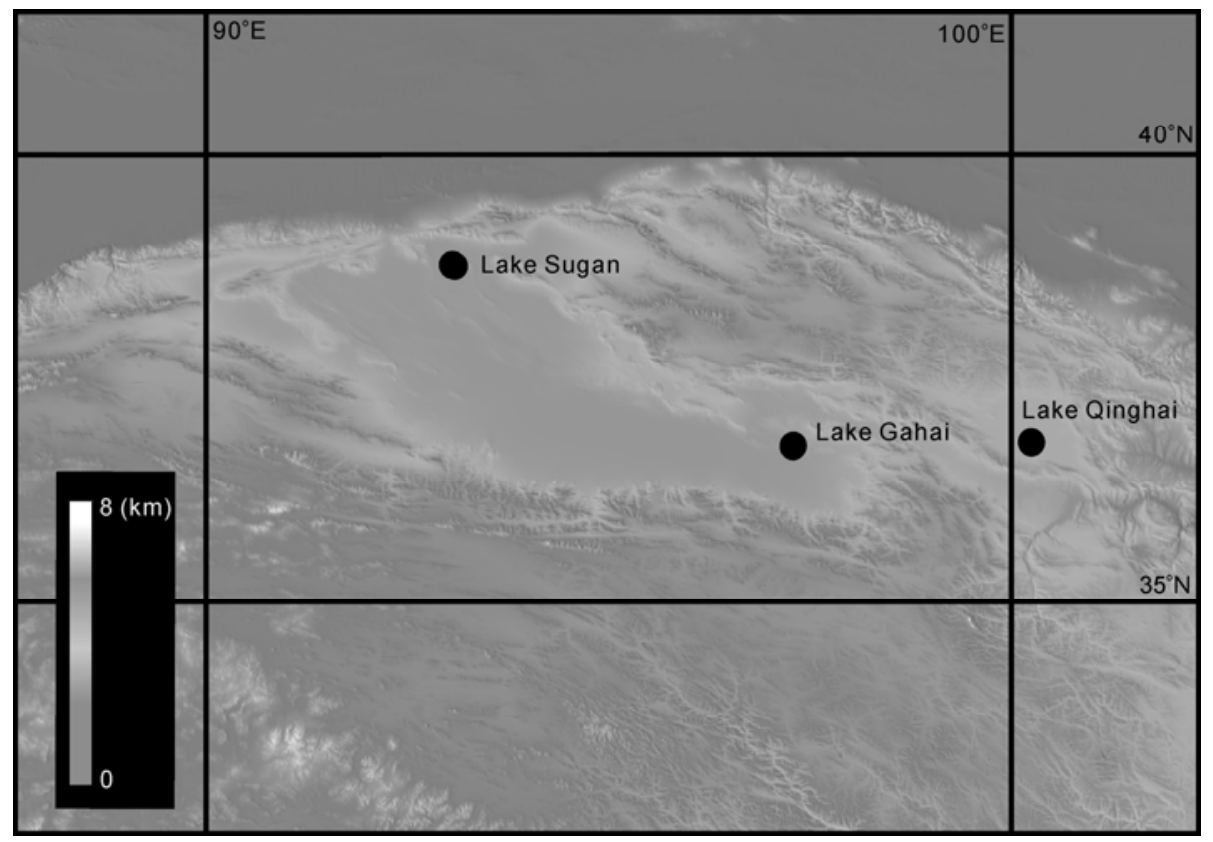

Figure 1 Map of the northern Tibetan Plateau. The locations of the study sites, Lake Gahai and Lake Sugan. Lake Qinghai is also shown.

\section{Sampling sites and methods}

The Qaidam Basin, where the two saline lakes, Lake Sugan $\left(38^{\circ} 52^{\prime} \mathrm{N}, 93^{\circ} 75^{\prime} \mathrm{E}, 2793 \mathrm{~m}\right.$ a.s.l.) and Lake Gahai $\left(37^{\circ} 08^{\prime} \mathrm{N}\right.$, $97^{\circ} 31^{\prime} \mathrm{E}, 2848 \mathrm{~m}$ a.s.1.), are located (Figure 1), exhibits extreme aridity and is currently outside the influence of the Asia summer monsoon [27]. Summer and annual air temperatures are $\sim 13-17^{\circ} \mathrm{C}$ and $\sim 2-5^{\circ} \mathrm{C}$, respectively, near the two lakes. Annual rainfall is generally less than $200 \mathrm{~mm}$ (only 20 mm around Lake Sugan), with $80 \%$ falling in summer, while potential evaporation exceeds $2000 \mathrm{~mm}$.

Lake sediment cores, $1.1 \mathrm{~m}$ from Lake Sugan (QHC09-2) and $2.5 \mathrm{~m}$ from Lake Gahai (QHC09-4), were retrieved from the lake center, and sub-sampled at every $0.5 \mathrm{~cm}$ continuously. Chronology for core QHC09-2 is established through ${ }^{210} \mathrm{~Pb} /{ }^{137} \mathrm{Cs}$ analyses on top 10 -cm sediments and 4 AMS- ${ }^{14} \mathrm{C}$ dates on bulk organic matter from remaining of the core, after correction of a 981-year reservoir effect determined by regression method and calibration to calendar years using the program CALIB 6.0.1 [28] (Figure 2(a)). For core QHC09-4, ${ }^{137} \mathrm{Cs}$ and excess ${ }^{210} \mathrm{~Pb}$ was only found at the top $3 \mathrm{~cm}\left(35.8 \mathrm{~Bq} / \mathrm{kg}\right.$ for ${ }^{137} \mathrm{Cs}$ and $102.4 \mathrm{~Bq} / \mathrm{kg}$ for excess ${ }^{210} \mathrm{~Pb}$ at the top) and thus ${ }^{210} \mathrm{~Pb}$ chronology cannot be established. We assume that the top $~ 50$-year missing during the coring process. The chronology of this core was established with 4 AMS $-{ }^{14} \mathrm{C}$ dates, after correction of an 1855-year reservoir effect (Figure 2(b)). We are aware that the assumption of a constant reservoir effect and a constant sedimentation rate through the late Holocene is not well justified, which is a common problem to most paleoclimatic
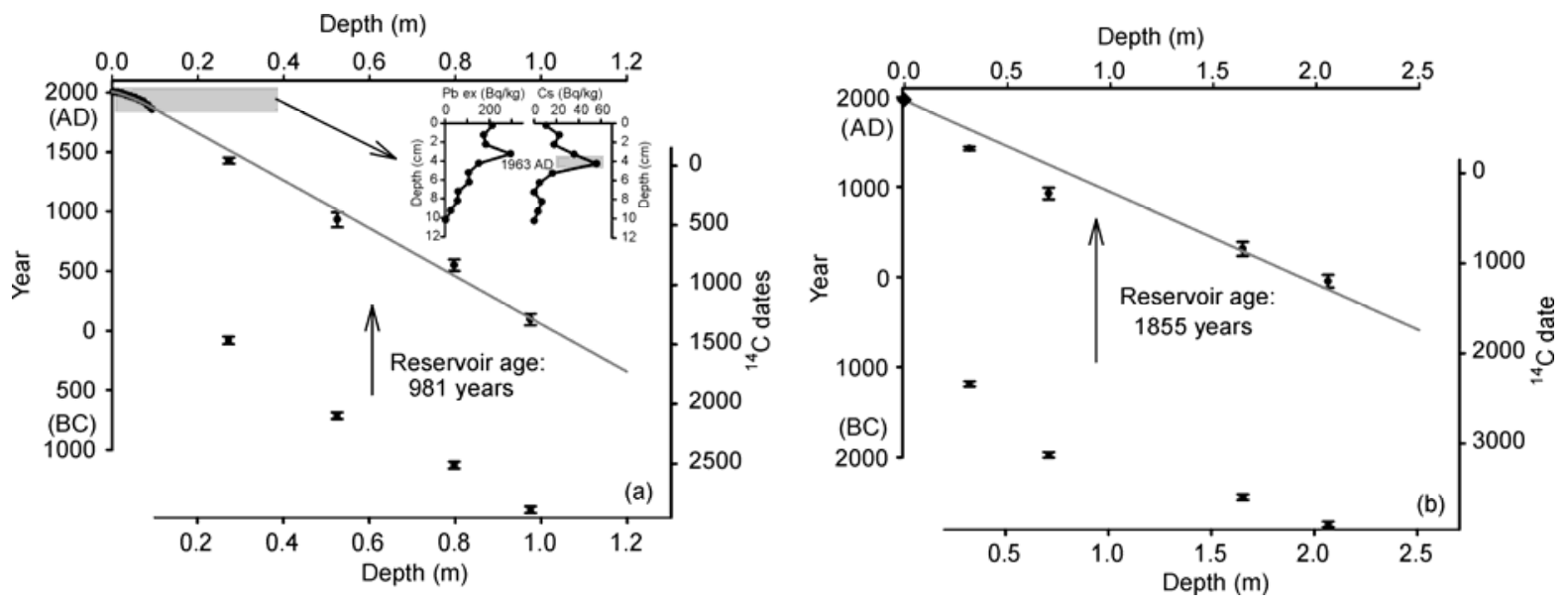

Figure 2 Age models for Lake Sugan (a) and Lake Gahai (b). 
studies on the Tibetan Plateau [29]. Most reservoir age correction approaches can only provide an estimate of the modern ${ }^{14} \mathrm{C}$ reservoir effect, and have failed to determine the reservoir age variability from the downcore [29]. However, in this study, we focus on identification of temperature change patterns which are not critically affected by the potential large age uncertainty.

Alkenone analyses followed the standard procedure by Liu et al. [30]. The total lipids were obtained through extraction of freeze-dried sediments $(\sim 2-6 \mathrm{~g})$ with organic solvents, hydrolyzed to remove alkenoates that could interfere with the identification of alkenones, and then separated into three fractions with silica gel column chromatography. The alkenone fraction was analyzed on Gas Chromatography (Agilent 7890 at the University of Hong Kong for Lake Gahai and Agilent 6890 at Institude of Earth Environment, Chinese Academy of Sciences for Lake Sugan), using $n-\mathrm{C}_{36}$ alkane as internal standard for quantification. The alkenone proxy was calculated as follow: $U_{37}^{k^{\prime}}=C_{37: 2}$ / $\left(C_{37: 2}+C_{37: 3}\right)$, where $\mathrm{C}_{37: 2}$ and $\mathrm{C}_{37: 3}$ are the contents of diand tri-unsaturated $\mathrm{C}_{37}$ alkenones respectively [31]. Analytical error is within 0.015 for $U_{37}^{k^{\prime}}$.

\section{Results}

Based on the derived chronology (Figure 2), the Lake Gahai core covers the last $\sim 2600$ years, whereas the Lake Sugan one covers the last $\sim 2200$ years. Sedimentation rates are $\sim 0.98 \mathrm{~mm} / \mathrm{a}$ in Lake Gahai and $\sim 0.5 \mathrm{~mm} / \mathrm{a}$ in Lake Sugan, respectively. Consequently, we achieved decadally-resolved records, with $\sim 5$ years sampling resolution from Lake Gahai and 10-30 years from Lake Sugan.

Our $U_{37}^{k^{\prime}}$-temperature records show substantial warm/cold oscillations on multi-centennial timescales during the last $\sim 2500$ years. $U_{37}^{k^{\prime}}$ values range from 0.08 to 0.25 in Lake Sugan and from 0.04 to 0.20 in Lake Gahai respectively (Figure 3(a), (b)), equivalent to variations in lake surface water temperature of up to $6^{\circ} \mathrm{C}$, based on the culture calibration equation [32] $\left(U_{37}^{k^{\prime}}=0.026 T-0.261\right)$. With such substantial variability, relative warm/cold periods can be clearly identified, including the current warm period after $A D$ 1850, the LIA between AD 1350-1850, the MWP between AD 700-1350, the Dark Ages Cold Period between AD $50-700$ [33], and the warm period before AD 50 based on the Lake Gahai record (Figure 3(b)). In particular, temperature oscillations within identified warm/cold periods, especially during the LIA, could be also observed, such as the warm intervals during AD 1590-1650 and AD 1750-1790. The two temperature records appear to have diverged after AD 1800. Exact reasons remain unclear, but we suspect that it might be related to the lower sedimentation rates in Lake Sugan, as well as potential chronology uncertainty. The two temperature records are broadly consistent with each other and the lower-resolution alkenone-based record from Lake
Qinghai [34] ( 300 km east to Lake Gahai) (Figure 1), particularly over the last 1500 years. Also our records are in accordance with the tree ring based temperature reconstructions in the mid-eastern Tibetan Plateau [35]. Further, our records agree well with the synthesized temperature reconstructions from the northeastern Tibetan Plateau [12] (Figure 3(c)) and the northern hemisphere [9] (Figure 3(d)).

\section{Discussion}

\section{1 $U_{37}^{k^{\prime}}$ for lake temperature reconstruction}

Alkenones are a series of long-chain unsaturated organic compounds produced by a limited number of algae which could faithfully record environmental conditions where the algae live $[31,36]$. Over the past two decades, the $U_{37}^{k^{\prime}}$ proxy has been widely used to quantitatively reconstruct sea surface temperature changes on various timescales, and proved to be one of the best temperature proxies to date. Although largely applied in marine settings previously, its capability for temperature reconstructions from lake sediments has been indicated by recent studies [30,32,34,37-45]. Chu et al. [37] found alkenones in 45 of 50 Chinese lakes and derived a relationship between $U_{37}^{k^{\prime}}$ and mean annual air temperatures: $U_{37}^{k^{\prime}}=0.025 T+0.153$ in saline lakes, with the slope similar to the excellent $U_{37}^{k^{\prime}}$-temperature relationship $\left(U_{37}^{k^{\prime}}=\right.$ $0.026 T-0.261)$ derived from culture experiments of lake species Chrysotila lamellosa under controlled growth temperatures [32]. Liu et al. [30,40] investigated in detail the $U_{37}^{k^{\prime}}$ distribution patterns in the Lake Qinghai region and Qaidam Basin. It appears that $U_{37}^{k^{\prime}}$ corresponds to lake temperature while salinity has little influence on $U_{37}^{k^{\prime}}$ [30]. The similar pattern of changes in $U_{37}^{k^{\prime}}$ and annual instrumental temperature records from nearby Lenghu Meteorological Station over the most recent 50-year where they overlap (Figure 4) further supports $U_{37}^{k^{\prime}}$ as a good proxy for temperature reconstructions in the Qaidam Basin. In this study, we interpret $U_{37}^{k^{\prime}}$ reflecting summer lake surface temperature, using the culture calibration from Sun et al. [32].

\subsection{The Medieval Warm Period}

Our two alkenone-based temperature records from the Qaidam Basin, together with the Lake Qinghai one [34], indicate persistently warm temperatures on the Northern Tibetan Plateau during the MWP (Figure 3), in accordance with the uncertainty analysis suggesting that the warmth during the 10-14th centuries might be comparable in magnitude to the warming of the last few decades [24]. These records join a growing body of such evidence $[4,8,10,12,24$, 46]. In particular, despite inconsistent with the spatial patterns derived from climate model-assisted reconstructions [8], the substantially warmer condition on the northern Tibetan Plateau, together with the relatively warmer conditions on 


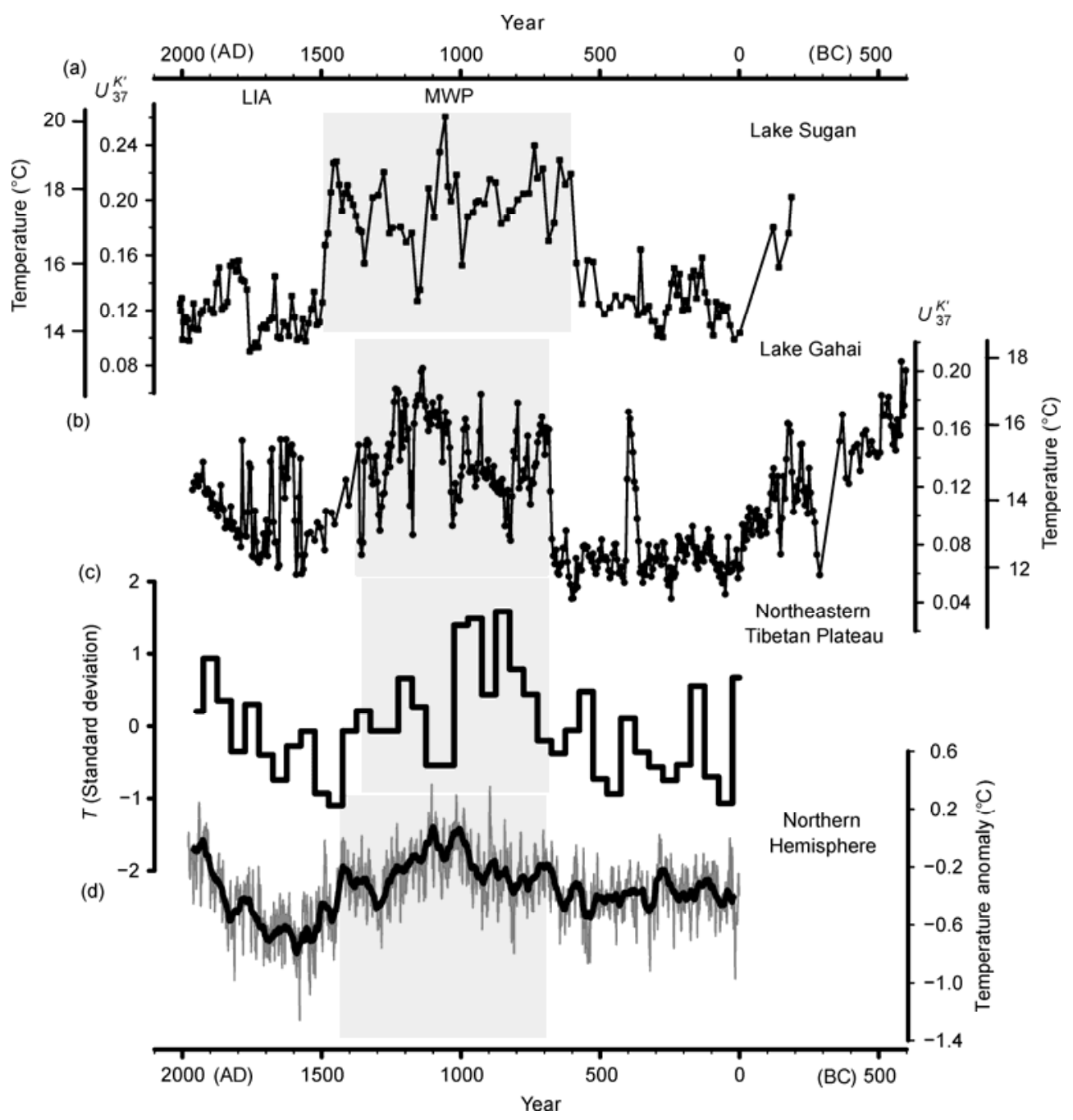

Figure 3 Late Holocene centennial-scale temperature variability. (a) $U_{37}^{k^{\prime}}$-temperature record from Lake Sugan; (b) $U_{37}^{k^{\prime}}$-temperature record from Lake Gahai; (c) 50-year average multi-proxy normalized temperature records from the Northeastern Tibetan Plateau [12]; (d) The Northern Hemisphere temperature reconstructions using multiple high and low resolution proxies [9]. Converted $U_{37}^{k^{\prime}}$-temperatures based on the calibration from Sun et al. [32]. The MWP is highlighted with light grey shadings.

Greenland [47], the persistent positive North Atlantic Oscillation mode [48], negative Southern Oscillation Index [49] and the prevailing La Niña-like conditions in the tropical Pacific [8,50], suggest anomalous climatic conditions during the MWP, beyond the climate variability captured by the recent warm period.

However, quantitative estimation of the warmth from our records is challenging. By comparing the temperature records within the MWP optimum, defined as 100-year peak values in the MWP (AD 1000-1100 for Lake Sugan and AD 1100-1200 for Lake Gahai), with temperature records from core sediments after $1950 \mathrm{AD}$ together with present surface water and sediments, we estimated that lake temperatures were higher by $\sim 4.0^{\circ} \mathrm{C}, \sim 1.9^{\circ} \mathrm{C}$ and $\sim 0.5^{\circ} \mathrm{C}$ for Lake Sugan, Gahai and Qinghai respectively during the MWP optimum. Although the same magnitude of temperature changes should not be expected, such large discrepancies may result from additional factors. For instance, lake water volume changes in small lakes, in addition to air temperatures, could potentially affect lake water temperature. The different sizes of the three lake volumes (Lake Sugan smallest whereas Lake Qinghai biggest) and their association of temperature with hydrological changes could potentially explain the observed discrepancies. During the warm MWP, lake levels in Lake Sugan and Gahai would have decreased due to associated dry conditions [22] and thus the warming signal would be further enhanced, while prevailing wet conditions in Lake Qinghai would have diminished the warming signal. Thus, the estimated warmth between the MWP relative to the recent level could be bracketed by the $\sim 1.9^{\circ} \mathrm{C}$ from Lake Gahai and $\sim 0.5^{\circ} \mathrm{C}$ from Lake Qinghai, probably closer to the lower end as the Lake Qinghai size is substantially larger and thus the lake volume effect should be smaller. Nevertheless, the observed marked temperature imply that the MWP was in a warm state beyond the climate variability captured by the recent warm 
period (Figure 4).

We argue that it is the dramatic hydrological changes in the Qaidam Basin that amplify the temperature signal recorded in lake waters, which allow our clear identification of temperature change patterns during the late Holocene. Also if elevated warming in northwestern China is a natural response to climate warming, then any warming trend, especially the recent global warming could lead to a significant high temperature over the northwestern China and perhaps cause a serious economic and ecological loss.

\subsection{Possible solar influenced temperature variations}

On multi-decadal and centennial timescales, temperature changes in our records appear to correspond to solar irradiance changes as inferred from residual $\Delta^{14} \mathrm{C}$ and ${ }^{10} \mathrm{Be}$ records [51,52]. Generally, warmer temperatures in the Qaidam Basin correspond to higher solar irradiance and vice versa. Our records appear to capture a large negative excursion in solar irradiance around BC 350 (Figure 5). Between BC 350 and $\mathrm{AD} 400$, both our records and solar irradiance show relatively less variability. Over the last 1600 years, the period with higher solar variability (Figure 5(a)), the records show an even better correspondence (Figure 5(b)). Within chronology uncertainty, potentially corresponding temperature changes could be identified for the solar minimums of Oort, Wolf, Spörer, Maunder and Dalton, and the Medieval and Modern solar maximums (Figure 5(a)). Therefore, there appears to be a possible link between solar irradiance and temperature variability, at least on the northern Tibetan Plateau, during the late Holocene.

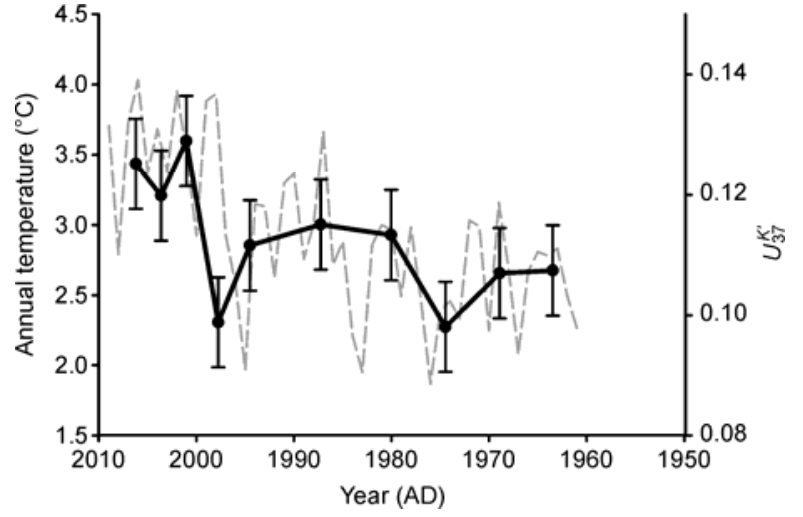

Figure 4 Comparison of alkenone-based temperature record (black solid line with error bars) from Lake Sugan with instrumental data (grey dashed line) from Lenghu meteorological station.

\section{Conclusion}

In this study, we have evaluated the validity of alkenone index $U_{37}^{k^{\prime}}$ as a temperature proxy and then used this proxy to reconstruct late Holocene temperature changes on the northern Tibetan Plateau. Based on the decadally-resolved, biomarker alkenone-based, temperature reconstructions, marked warm periods and cold periods can be clearly identified over the last $\sim 2500$ years. Our records show that the regional temperatures during the MWP exceeded those in the recent warm period. The estimated warmth during the MWP optimum relative to the recent level could be bracketed by the $\sim 1.9^{\circ} \mathrm{C}$ estimated from Lake Gahai and $\sim 0.5^{\circ} \mathrm{C}$ from Lake Qinghai. Therefore, the MWP warmth was

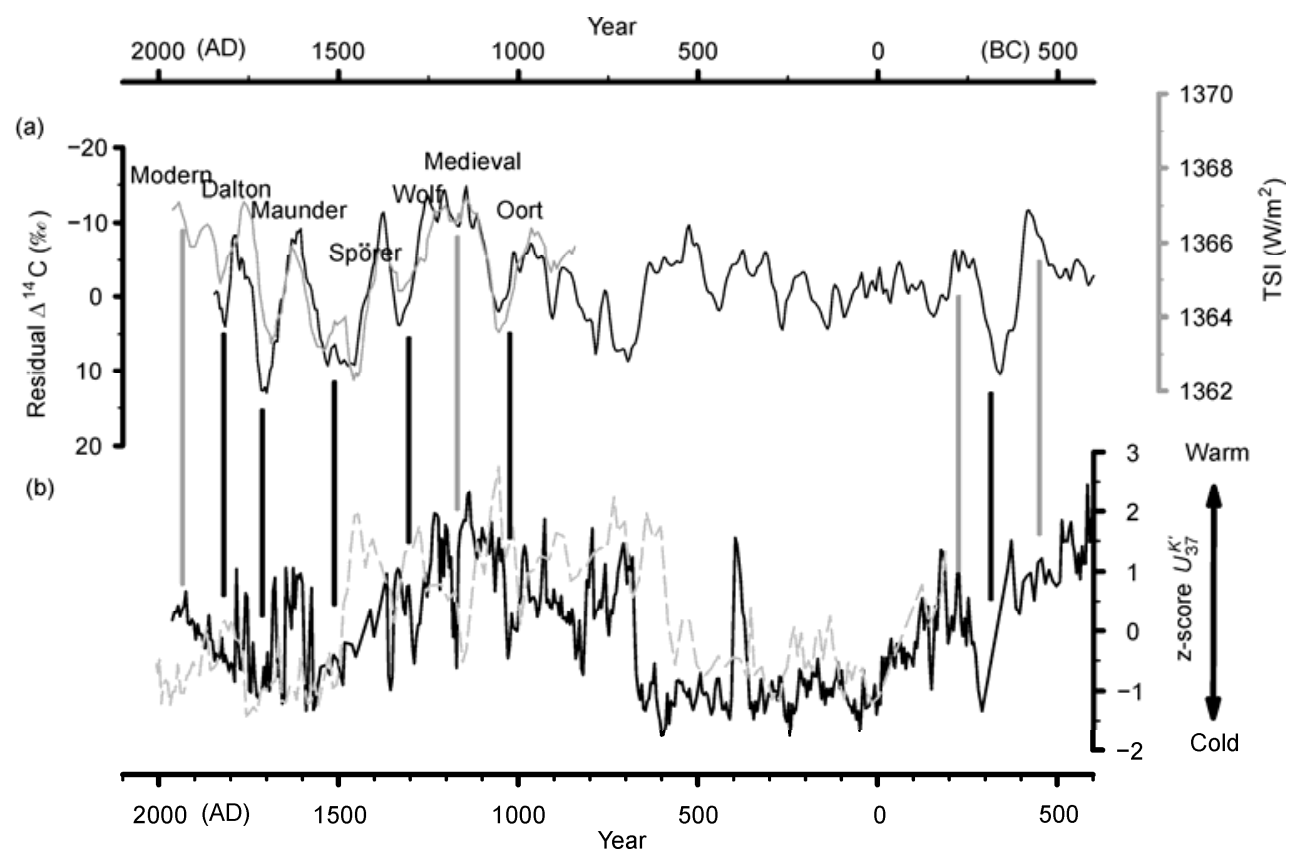

Figure 5 Comparisons of the solar irradiance with temperature records. (a) The residual $\Delta^{14} \mathrm{C}$ record [52] (black) and reconstructed total solar irradiance (TSI) records [51] (grey); (b) standardized $U_{37}^{k^{\prime}}$ records from Lake Gahai (black solid line) and Lake Sugan (grey dashed line). 
probably in a climate state beyond the climate variability captured by the recent warm period, joining a growing body of such evidence elsewhere. Further, the temperature variability appears to correspond to solar irradiance changes, suggesting a possible link between the two, at least on the northern Tibetan Plateau, during the late Holocene.

We thank referees for their constructive reviews and Profs. L. Sun and Z. Xie of USTC for ${ }^{210} \mathrm{~Pb}^{137} \mathrm{Cs}$ analyses. This work was supported by the National Basic Research Program of China (2010CB833406, 2010CB428902), and Hong Kong Rearch Grants Council (HKU 703809P). This work was also partially supported by the Special Equipment Grant from the University Grants Committee of the Hong Kong Special Administrative Region, China (SEG_HKU01) and by the CAS/SAFEA International Partnership Program for Creative Research Teams (KZZD-EW-TZ03).

1 Buntgen U, Tggel W, Nicolussi K, et al. 2500 years of European climate variability and human susceptibility. Science, 2011, 331: 578582

2 Crowley T J. Causes of climate change over the past 1000 years. Science, 2000, 289: 270-277

3 Dai Y, Zhang Y, Ge J Y. Decadal-scale variability of warm season temperature in Beijing over the past 2650 years. Chin Sci Bull, 2011, 56: $2366-2370$

4 Esper J, Cook E R, Schweingruber F H. Low-frequency signals in long tree-ring chronologies for reconstructing past temperature variability. Science, 2002, 295: 2250-2253

5 Ge Q S, Zhang X Z, Hao Z X, et al. Rates of temperature change in China during the past 2000 years. Sci China Earth Sci, 2011, 54: $1627-1634$

6 Liu Y, Cai Q F, Song H M, et al. Amplitudes, rates, periodicities and causes of temperature variations in the past 2485 years and future trends over the central-eastern Tibetan Plateau. Chin Sci Bull, 2011, 56: 2986-2994

7 Mann M E, Jones P D. Global surface temperatures over the past two millennia. Geophys Res Lett, 2003, 30: 1820

8 Mann M E, Zhang Z, Rutherford S, et al. Global signatures and dynamical origins of the Little Ice Age and Medieval Climate Anomaly. Science, 2009, 326: 1256-1260

9 Moberg A, Sonechkin D M, Holmgren K, et al. Highly variable Northern Hemisphere temperatures reconstructed from low- and high-resolution proxy data. Nature, 2005, 433: 613-617

10 Oppo D W, Rosenthal Y, Linsley B K. 2000-year-long temperature and hydrology reconstructions from the Indo-Pacific warm pool. Nature, 2009, 460: 1113-1116

11 Qiang M R, Chen F H, Zhang J W, et al. Climatic changes documented by stable isotopes of sedimentary carbonate in Lake Sugan, northeastern Tibetan Plateau of China, since 2 ka BP (in Chinese). Chin Sci Bull (Chin Ver), 2005, 50: 1930-1939

12 Yang B, Achim B, Shi Y F. Late Holocene temperature fluctuations on the Tibetan Plateau. Quat Sci Rev, 2003, 22: 2335-2344

13 Zhu H F, Zheng Y H, Shao X M, et al. Millennial temperature reconstruction based on tree-ring widths of Qilian juniper from Wulan, Qinghai Province, China. Chin Sci Bull, 2008, 53: 3914-3920

14 Magny M, Arnaud F, Holzhauser H, et al. Solar and proxy-sensitivity imprints on paleohydrological records for the last millennium in west-central Europe. Quat Res, 2010, 73: 173-179

15 Shindell D T, Schmidt G A, Mann M E, et al. Solar forcing of regional climate change during the Maunder Minimum. Science, 2001, 294: 2149-2152

16 Wang Y J, Cheng H, Edwards R L, et al. The Holocene Asian monsoon: links to solar changes and north Atlantic climate. Science, 2005, 308: 854-857

17 Waple A M, Mann M E, Bradley R S. Long-term patterns of solar irradiance forcing in model experiments and proxy based surface temperature reconstructions. Clim Dyn, 2002, 18: 563-578
18 Zhang P Z, Cheng H, Edwards R L, et al. A test of climate, sun, and culture relationships from an 1810-year Chinese cave record. Science, 2008, 322: 940-942

19 Zhao C, Yu Z C, Zhao Y, et al. Possible orographic and solar controls of Late Holocene centennial-scale moisture oscillations in the northeastern Tibetan Plateau. Geophys Res Lett, 2009, 36: L21705

20 Jones P D, Briffa K R, Osborn T J, et al. High-resolution palaeoclimatology of the last millennium: A review of current status and future prospects. The Holocene, 2009, 19: 3-49

21 von Storch H, Zorita E, Jones J M, et al. Reconstructing past climate from noisy data. Science, 2004, 306: 679-682

22 Chen F H, Chen J H, Holmes J, et al. Moisture changes over the last millennium in arid central Asia: A review, synthesis and comparison with monsoon region. Quat Sci Rev, 2010, 29: 1055-1068

23 Ding Q H, Wang B. Circumglobal teleconnection in the Northern Hemisphere summer. J Clim, 2005, 18: 3483-3505

24 Ge Q S, Zheng J Y, Hao Z X, et al. Temperature variation through 2000 years in China: An uncertainty analysis of reconstruction and regional difference. Geophys Res Lett, 2010, 37: L03703

25 Yang B, Tang L Y, Li C H, et al. An ice-core record of vegetation and climate changes in the central Tibetan Plateau during the last 550 years. Chin Sci Bull, 2010, 55: 1167-1177

26 Zhang D E. Winter temperature changes during the last 500 years in south China (in Chinese). Chin Sci Bull (Chin Ver), 1980, 25: 497500

27 Tian L, Masson-Delmotte V, Stievenard M, et al. Tibetan Plateau summer monsoon northward extent revealed by measurements of water stable isotopes. J Geophys Res, 2001, 106: 28081-28088

28 Stuiver M, Reimer P J. Extended ${ }^{14} \mathrm{C}$ data-base and revised Calib 3.0 ${ }^{14} \mathrm{C}$ age calibration program. Radiocarbon, 1993, 35: 215-230

29 Hou J Z, D' Andrea W J, Liu Z H. The influence of ${ }^{14} \mathrm{C}$ reservoir age on interpretation of paleolimnological records fron the Tibetan Plateau. Quat Sci Rev, 2012, 48: 67-79

30 Liu W G, Liu Z H, Wang H Y, et al. Salinity control on long-chain alkenone distributions in lake surface waters and sediments of the northern Qinghai-Tibetan Plateau, China. Geochim Cosmochim Acta, 2011, 75: 1693-1703

31 Prahl F G, Muehlhausen L A, Zahnle D L. Further evaluation of long-chain alkenones as indicators of paleoceanographic conditions. Geochim Cosmochim Acta, 1998, 52: 2303-2310

32 Sun Q, Chu G Q, Liu G X, et al. Calibration of alkenone unsaturation index with growth temperature for a lacustrine species, Chrysotila lamellosa (Haptophyceae). Org Geochem, 2007, 38: 1226-1234

33 Lamb H H. Climatic History and The Future. Princeton: Princeton University Press, 1985

34 Liu Z H, Henderson A C G, Huang Y S. Alkenone-based reconstruction of Late-Holocene surface temperature and salinity changes in Lake Qinghai, China. Geophys Res Lett, 2006, 33: L09707

35 Liu Y, An Z S, Linderholm H W, et al. Annual temperatures during the last 2485 years in the mid-eastern tibetan plateau inferred from tree rings. Sci China Ser D-Earth Sci, 2009, 52: 348-359

36 Brassell S C, Eglinton G, Marlowe I T, et al. Molecular stratigraphy: A new tool for climatic assessment. Nature, 1986, 320: 129-133

37 Chu G Q, Sun Q, Li S Q, et al. Long-chain alkenone distributions and temperature dependence in lacustrine surface sediments from China. Geochim Cosmochim Acta, 2005, 69: 4985-5003

38 D'Andrea W J, Huang Y S. Long chain alkenones in Greenland lake sediments: Low delta $\mathrm{C}-13$ values and exceptional abundance. Org Geochem, 2005, 36: 1234-1241

39 D'Andrea W J, Huang Y S, Fritz S C, et al. Abrupt Holocene climate change as an important factor for human migration in West Greenland. Proc Natl Acad Sci USA, 2011, 108: 9765-9769

40 Liu W G, Liu Z H, Fu M Y, et al. Distribution of the C37 tetraunsaturated alkenone in Lake Qinghai, China: A potential lake salinity indicator. Geochim Cosmochim Acta, 2008, 72: 988-997

41 Pearson E J, Juggins S, Farrimond P. Distribution and significance of long-chain alkenones as salinity and temperature indicators in Spanish saline lake sediments. Geochim Cosmochim Acta, 2008, 72: 4035-4046 
42 Sheng G Y, Cai K Q, Yang X X, et al. Long-chain alkenones in Hotong Qagan Nur Lake sediments and its paleoclimatic implications. Chin Sci Bull, 1999, 44: 259-263

43 Toney J L, Huang Y S, Fritz S C, et al. Climatic and environmental controls on the occurrence and distributions of long chain alkenones in lakes of the interior United States. Geochim Cosmochim Acta, 2010, 74: 1563-1578

44 Toney J L, Theroux S, Andersen R A, et al. Culturing of the first 37:4 predominant lacustrine haptophyte: Geochemical, biochemical, and genetic implications. Geochim Cosmochim Acta, 2012, 78: 51-64

45 Zink K G, Leythaeuser D, Melkonian M, et al. Temperature dependency of long-chain alkenone distributions in Recent to fossil limnic sediments and in lake waters. Geochim Cosmochim Acta, 2011, 65: 253-265

46 Kang X C, Grumlich L J, Sheppard P R. A 1835-yr tree-ring chronology and its preliminary analysis in Dulan region, Qinghai (in Chinese). Chin Sci Bull (Chin Ver), 1997, 42: 1089-1091
47 Kobashi T, Kawamura K, Severinghaus J P, et al. High variability of Greenland surface temperature over the past 4000 years estimated from trapped air in an ice core, Geophys Res Lett, 2011, 38: L21501

48 Trouet V, Esper J, Graham N E, et al. Persistent positive north atlantic oscillation mode dominated the medieval climate anomaly. Science, 2009, 324: 78-80

49 Yan H, Sun L G, Wang Y H, et al. A record of the Southern Oscillation Index for the past 2000 years from precipitation proxies. Nat Geosci, 2011, 4: 611-614

50 Mann M E, Cane M A, Zebiak, et al. Volcanic and solar forcing of the tropical Pacific over the past 1000 years. J Clim, 2005, 18: 447456

51 Bard E, Raisbeck G, Yiou F, et al. Solar irradiance during the last 1200 years based on cosmogenic nuclides. Tellus B, 2000, 52: 985-992

52 Reimer P J, Baillie M G L, Bard E, et al. IntCal04 terrestrial radiocarbon age calibration, 0-26 cal ka BP. Radiocarbon, 2004, 46: 1029-1058

Open Access This article is distributed under the terms of the Creative Commons Attribution License which permits any use, distribution, and reproduction in any medium, provided the original author(s) and source are credited. 